\title{
"Product placement in computer/video games: an analysis of the impact on customers purchasing decision"
}

\begin{tabular}{|c|c|}
\hline AUTHORS & $\begin{array}{l}\text { Angelina Chernikova iD https://orcid.org/0000-0002-8266-3961 } \\
\text { Murilo Branco (D https://orcid.org/0000-0002-7816-5097 }\end{array}$ \\
\hline ARTICLE INFO & $\begin{array}{l}\text { Angelina Chernikova and Murilo Branco (2019). Product placement in } \\
\text { computer/video games: an analysis of the impact on customers purchasing } \\
\text { decision. Innovative Marketing , 15(3), 60-70. doi:10.21511/im.15(3).2019.05 }\end{array}$ \\
\hline DOI & http://dx.doi.org/10.21511/im.15(3).2019.05 \\
\hline RELEASED ON & Monday, 23 September 2019 \\
\hline RECEIVED ON & Thursday, 25 July 2019 \\
\hline \multirow[t]{2}{*}{ ACCEPTED ON } & Thursday, 12 September 2019 \\
\hline & $(\mathrm{cc}) \overline{E Y Y}^{\mathrm{E}}$ \\
\hline LICENSE & $\begin{array}{l}\text { This work is licensed under a Creative Commons Attribution } 4.0 \text { International } \\
\text { License }\end{array}$ \\
\hline JOURNAL & "Innovative Marketing " \\
\hline ISSN PRINT & $1814-2427$ \\
\hline ISSN ONLINE & $1816-6326$ \\
\hline PUBLISHER & LLC "Consulting Publishing Company "Business Perspectives" \\
\hline FOUNDER & LLC “Consulting Publishing Company "Business Perspectives" \\
\hline & Еニ: \\
\hline NUMBER OF REFERENCES & NUMBER OF FIGURES \\
\hline 28 & 3 \\
\hline
\end{tabular}

(C) The author(s) 2022. This publication is an open access article. 


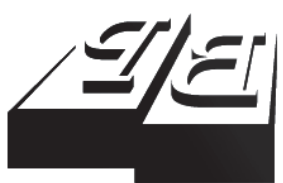

BUSINESS PERSPECTIVES

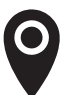

LLC "CPC "Business Perspectives" Hryhorii Skovoroda lane, 10, Sumy, 40022, Ukraine

www.businessperspectives.org

Received on: $25^{\text {th }}$ of July, 2019 Accepted on: $12^{\text {th }}$ of September, 2019

(C) Angelina Chernikova, Murilo Branco, 2019

Angelina Chernikova, Msc, International Business Management Faculty, Marketing Department, Marbella International University Centre, Spain.

Murilo Branco, Professor, International Business Management Faculty, Marketing Department Marbella International University Centre, Spain.

\section{(ㄷ) (i)}

This is an Open Access article, distributed under the terms of the Creative Commons Attribution 4.0 International license, which permits unrestricted re-use, distribution, and reproduction in any medium, provided the original work is properly cited.

\section{PRODUCT PLACEMENT IN COMPUTER/VIDEO GAMES: AN ANALYSIS OF THE IMPACT ON CUSTOMERS PURCHASING DECISION}

\begin{abstract}
The video game and virtual reality became a new way of doing marketing considering their growing popularity and the advances of new technologies in the past few decades. In this paper is presented a research that investigates the impact of product placement in video games on gamers' decisions on the purchase of goods from advertised. This research is focused on two of the most played games nowadays: FIFA 19 and Final Fantasy XV. A survey with 465 respondents was conducted to understand the antecedents that impact the purchase decision considering the stimulus originated from the product placement. To conduct the survey, a framework was designed based in the extant literature reviewed and finally considering the constructs of product placement, quality of virtual reality, brand recognition, brand familiarity, emotional response and purchase frequency. The results of the study suggest that gamers generally respond positively towards product placement and that product placement can indirectly impact emotional responses that will impact on consumer's purchase intention. Hence, advertising in the video game enhances brand recognition and the perception of virtual reality. The framework presented in this paper represents the theoretical contribution of this paper, relating different concepts in the theory of product placement to the purchase intention. Therefore, the findings on this paper can help managers to find the best way to reach customers by improving the product placement strategy in the video games.
\end{abstract}

Keywords

JEL Classification purchasing decision, video games, product placement, brand awareness, virtual reality

M370

\section{INTRODUCTION}

Advertising technologies are constantly changing. The effectiveness of advertising depends on how this advertising satisfies the audience, how much it corresponds to its intelligence level and needs (Newell et al., 2006; Williams et al., 2011). Currently, explicit advertising and traditional advertising technologies could be less effective in many cases they can present an aggressive approach (Kit \& Qui P'ng, 2014). In addition, new generations of consumers are harder to manipulate as nowadays they understand better how advertising works, and they don't accept the traditional marketing (Parreno, 2015). Even when gamers perceive the hidden advertising, they would prefer such approach to explicit advertising (Marti-Parreno et al., 2017). In this sense, traditional advertising can is turning obsolete.

The product placement gives brands an opportunity to distinguish themselves from competitors in tough competitive conditions (Babacan, Akcali, \& Baytekin, 2012). For several decades, researchers 
have proposed different definitions of this advertising technology, and they can vary greatly. According to Newell et al. (2006), the product placement is the insertion of branded products or services into mass media content with the intention of influencing consumer attitude or behavior.

Product placement has been used for more than a century. Cinema was the most frequently used advertising media for most of this time. Product placement became an industry after the success of hidden advertising in E.T. the Extra-Terrestrial (1982) when a little-known brand of sweets became popular (Newell, Salmon, \& Chang, 2006). Even though the product placement industry was formed only in the 1980s, it is worth noting that in the movies, this advertising strategy was used from the very beginning of the cinema history, and in the literature, it was present at an earlier time. In addition to video games, and movies, product placement technology is used on television, music, video clips, books and comics. It is important to note that the products promoted this way must have a real equivalent. Products and brands are placed in the plot of works of art and mass culture products in such a way that such advertising not only attracts interest to them, but also helps to achieve specific commercial goals. The hidden nature is a distinctive feature of product placement. The audience shouldn't identify the product placement as an advertisement, as it should act softly, like native advertising.

In the past few decades, video games have become an equally popular form of entertainment. The game culture has spread among people of different ages. Now, potential users of any brand can play video games, which make product placement a potentially effective advertising. However, it is important to note that product placement is always focused on a wide audience, and therefore it is integrated into mass culture products. However, the effectiveness of product placement is central in related studies. In our research we want to understand in which cases product placement in video games are effective: What influences the effectiveness of this advertising strategy? How can it impact the purchasing decisions made by gamers?

To accomplish the aim of the study, we wanted to understand the impact of product placement in gamers' decisions on the purchase of goods from advertised brands. The research is relevant because its topic corresponds to the current situation in marketing, the use of new technologies and the perception of gamers as target market for related marketed brands.

\section{LITERATURE REVIEW}

Product placement is related to the type of advertising that consists of the placement of commercial information in content perceived by viewers as non-advertising and as entertainment (Lehu, 2009; Kit \& Qui P'ng, 2014). Product placement has more risks involved compared to the traditional advertising, and, in recent decades has been used frequently in television programs, cinema, video games, together with other virtual reality products, and so on. Marketers are working in the improvement of the use of technologies related to product placement in such a way that advertising does not seem obvious at all (Williams et al., 2011; Newell, Salmon, \& Chang, 2006).

Williams et al. (2011) appraise product placement as a specific type of advertisement in terms of its aims, effectiveness, and drawbacks. There are several goals for product placement as attracting the audience's attention to the brand, improving brand awareness or consumer memory for brands and products, creating instant recognition of a product or a brand, changing the overall brand assessment of consumers, influencing consumer behavior and intentions. However, this kind of advertising is associated with uncertainty and marketers should be aware that the effectiveness of product placement couldn't be predicted with great precision (Lehu, 2009; Kit \& Qui P'ng, 2014; Nelson, 2002).

Nelson (2002) considers that the semantic structure of the video game helps to improve the integration of brands. The gameplay can integrate both, new or not well-known brands, increasing their recognition since the video game audi- 
ence pays attention to what they see while playing. According to the survey conducted by the Nelson (2002), players do not consider the practice of product placement to be unethical or deceiving them. On the contrary, virtual reality becomes more similar to life when integrating brand names into video games, increasing the realism of games.

The product placement in video games is not a new manifestation of the advertising strategy: product placement has been used in video games since the 1980s (Lehu, 2009). Actuallly some games are created specifically with the advertising purpose to promote a brand or product also called advergames (Kit \& Qui P’ng, 2014). Advertising can be integrated into the game, in other cases, which is not created only for advertising reasons. Marketers can fin difficult to integrate a brand into the plot of a game, as this requires creativity and professionalism from developers. Product placement should also consider that it must not distract players. Techniques of visual or verbal levels are used to present the product placement in video games. Most often, ads are placed in video games using banners in the virtual reality or it can be less obvious, for example, when the player's character uses advertised products in everyday life (Nelson, 2012; Machleit \& Wilson, 1988; Lehu, 2009). The effectiveness of product placement is also related to the level of emotional involvement of players in the plot of the game.

Virtual reality is becoming vivid, dynamic and attractive from year to year, constantly changing, and improving technologically and aesthetically, improving the use of product placement as marketing strategy (Nelson, 2002). Hence, the game culture is also changing: in recent years, games have attracted not only children and teenagers, but also people of previous generations. Economically, the gaming industry is already surpassing the cinema industry (Nelson, 2002).

\subsection{Product placement and consumer behavior}

The consumer behavior is linked to the gradual process of a purchase decision, which occur through different stages like understanding the need for a product, finding the appropriate product, evaluating alternatives from different brands and evaluating consumer's buying decision (Machleit \& Wilson, 1988) The product placement can impact consumers decision, depending on the individual attitude of the consumer considering the relevance of the advertising (Nelson, 2002; Kit \& Qui P’ng, 2014; Winkler \& Buckner, 2006).

The cost of producing games can be reduce through the product placement and gamers understand that (Nelson, 2002). However, some gamers perceive advertising offensive and intrusive, but others find it as an element that enhances the atmosphere of the game (Kit \& Qui P'ng, 2014; Winkler \& Buckner, 2006). Gamers seems to not to have their experiences affected by advertising in the game, as tit generally don't distract players from the gameplay. Considering that improving brand awareness is the main goal of product placement adverts in video games, this kind of promotion can be considered effective as it helps to achieve the desired effect (Glass, 2007; Gupta \& Lord, 1998). However, the effectiveness of product placement in video games does not happen in all cases. Several studies alert to the problem of product placement's performance (Glass, 2007; Gupta \& Lord, 1998; Kit \& Qui P’ng, 2014; Karrh, McKee, \& Pardun, 2003). In general, the advertising strategy using product placement is efficient, being widely used in modern marketing and covers all new areas (Nelson, 2002).

Winkler and Buckner (2006) analyzed the product placement in video games and the consequently consumer attitudes and how they perceive the brand messages. The product placement increases the positive consumer attitudes already established towards brands, but this kind of marketing strategy is not effective enough when advertising little-known brands.

\subsection{The virtual reality}

More than usually, players immerse in the virtual reality (VR) in the process of gaming. However, the intensity of the experience is related to the content representation models within virtual reality and may vary depending on the kind of used technologies (Dilworth, 2009). The product placement induces players to interact with brands, becoming part of their virtual characters' lives. Actually, the VR imitates the real life, and such advertising 
strategy can have a greater effectiveness since the players are in a state of heightened vigilance while playing (Wang \& Chen, 2019; Nelson, 2002; Lehu, 2009). Nowadays, VR and video games become the most promising channels for advertising, according to Wang and Chen (2019).

"A placement in a videogame offers additional advantages over the same placement in a film. The player generally pays much closer attention than the viewer. The possibility of control and the concomitant feeling of mastering the environment are greater for players. They must construct a mental map of the game space as if it were a real space in three dimensions, each constitutive element of which is important" (Lehu, 2009, p. 181).

Video games, essentially, are virtual reality spaces. Thus, like VR, video games provide audience the tools to interact with the content, in contrast to the audience of other medias, like movies and television (Wang \& Chen, 2019). Consequently, the VR interaction explains the effectiveness of product placement in video games.

The main feature of the format of video games is that the player chooses a character whose avatar he uses in the game. Therefore, the interactive media content impacts positively on the persuasion effect of messages posted in the advertising (Winkler \& Buckner, 2006; Lehu, 2009; Wang \& Chen, 2019). Thus, brand awareness can be enhanced through the players immersion in the game combined to product. However, due to the involvement in the gameplay, players are not easily distracted from what is happening and may just ignore the product placement. The good product placement must integrate advertised brands carefully into the plot, becoming an integral part of the virtual history (Wang \& Chen, 2019).

In fact, the realism of the virtual reality is enhanced by the use of brands, as users are involved in the process of building meanings, and, while playing the game, they can positively perceive brands value when the right product placement strategy is applied (Wang \& Chen, 2019). The product placement in the VR has a connection with the concept of branded entertainment, which means combining entertainment content (games) with advertising messages (product placement).

\subsection{Product placement and brand interaction}

Researches address studies to understand how advertising influences the effect of familiarity with the brand among the audience on the product placement field (Marti-Parreno et al., 2017). In some cases, games are entirely devoted to the brand or the product placement is repeated several times throughout the game providing the effect of gamers to become acquainted with the brand. Thus, the audience of video games is expanding constantly at the expense of people of different generations and product placement has been used as brand familiarity strategy very often (Wang \& Chen, 2019; Marti-Parreno et al., 2017).

In addition, previous consumer experience is determined by familiarity with the brand (Mau et al., 2008). If the player connects himself with the brand during the game, his attitude towards the brand can be affected by the previous experience (Marti-Parreno et al., 2017). Thus, trust can also be impacted by product placement helping to increase reliability on consumers when they first purchase a brand product that they've seen in the game (Nelson, 2002; Machleit \& Wilson, 1988).

Most of the research on product placement in video games considers how the advertising in the game influences the memorability of brands (Marti-Parreno et al., 2017, Mau et al., 2008, etc.). Mau et al. (2008), Marti-Parreno et al. (2017) found that unfamiliar brands can achieve good results concern to positive attitude from game players as a result of product placement (Mau et al., 2008).

The researchers also pay attention to the analysis of the emotional reaction of players related to advertising messages and attitudes towards the brand. Machleit and Wilson (1988) found that advertising in video games evokes different kinds of emotional sensations in audiences of various types. The analysis of positive emotions is important in connection with the understanding of the type of product placement advertising. In theory, product placement reveals a desire of game players to imitate characters (Mau et al., 2008). 


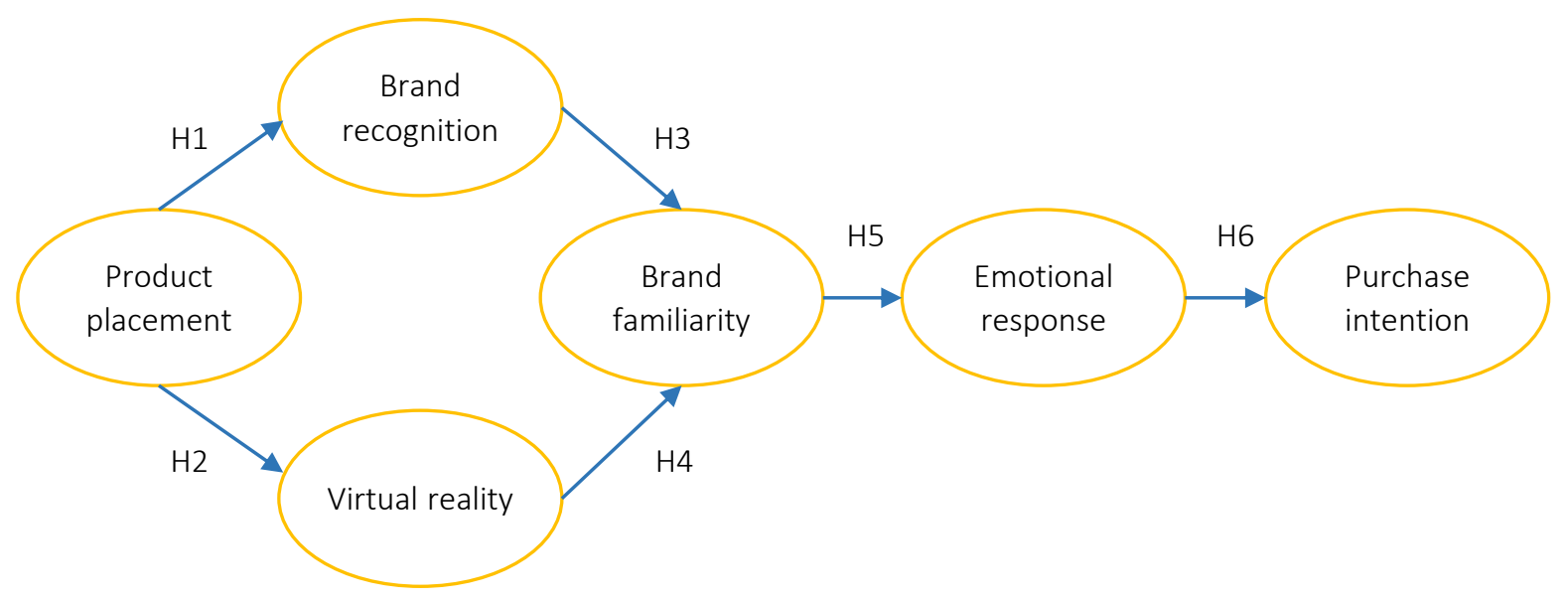

Figure 1. Conceptual model and hypotheses

\subsection{Conceptual model and hypotheses}

To achieve the aim of the study, we designed a framework based on the literature review. Purchasing Intention can be influenced by multiple factors. These factors are presented in variables. To analyze the impact of product placement in the purchase intention, we developed 6 hypotheses (Figure 1) explained next.

\subsubsection{Product placement and its impact on brand recognition and quality of VR}

Brand recognition can be regarded as a first step of advertising influence process. To attract gamers in any way, brand should be recognized by them (Machleit \& Wilson, 1988). The product placement's effectiveness can't be denied (Glass, 2007; Gupta \& Lord, 1998; Karrh et al., 2003). However, researchers argue about the measuring of effectiveness of this technology. Brand recognition is studied as he first stage of the audience's reaction on product placement (H1). The virtual reality is related to the gamer's experience in the video game and, when gamers see advertisements placed in their games interaction, they become part of their virtual avatars increasing the perception of reality (Wang \& Chen, 2019; Nelson, 2002; Lehu, 2009). Hence, advertising in games can have a great effect in the construction of the virtual reality in the game (H2). To understand the two relationships presented above, we developed two following hypotheses:
H1: The product placement perception has a positive impact on brand recognition.

H2: The product placement perception has a positive impact on virtual reality.

\subsubsection{Brand recognition impact on brand familiarity}

According to some authors (Laroche et al., 2006), brand familiarity is a very important construct related to the consumer behavior. Brand Familiarity was added as a variable in our framework, because it may be not enough to recognize a brand - it is also important to memorize it, to know the idea of the brand before purchasing (Williams et al., 2011). The brand familiarity is related to the result of increasing brand visibility, attention and interest (Glass, 2007; Mackay et al., 2009), and this is one of the purposes of product placement. To make brand familiar, brand recognition should be reached first. Thus, we can assume that brand familiarity is the next step that can be achieve after brand recognition. The following hypothesis explores this relationship in our framework:

H3: Brand recognition has a positive impact on brand familiarity.

\subsubsection{Quality of virtual reality impact on brand familiarity}

Wang and Chen (2019) discuss VR as a space for placing brands for promotion. According to the authors, quality of VR is important for engage- 
ment of the audience and creation of high brand awareness. Engagement gives new opportunities to marketers; when gamers are immersed in the game, they can recognize and memorize brands easily. Based on this research, we added the following hypothesis in our framework:

H4: Quality of virtual reality has a positive impact on brand familiarity.

\subsubsection{Brand familiarity impact on emotional response}

Audience's feelings and attitudes towards advertising were studied by Machleit and Wilson (1988) who consider feelings and emotions caused by advertising, direct effects of marketing information on emotional response. We may assume that brands familiar to audience cause positive emotions in gamers. So, we add this hypothesis in our framework.

\section{H5: Brand familiarity has a positive impact on emotional response.}

\subsubsection{Emotional response on purchasing intention}

Marketers generate various affective responses in the audience with the use of advertising (Machleit \& Wilson, 1988). Being a final stage of consuming process (except the very act of consumption), Purchasing intention is a sign of users' empathy towards the advertised brand. So, the final hypothesis was designed on the basis on purchasing intention variable.

H6: Emotional response has a positive impact on purchasing intention.

\section{METHODOLOGY}

Research epistemology used in this paper is both positivist and interpretivist. We used a quantitative approach to obtain data and analyze the hypotheses mentioned in the previous section and the framework developed in this study. Interpretivism is a modern analogy to positivism, which is widely used in contemporary research in various fields. Interpretivism is becoming increasingly popular in the newest studies. Interpretive methods assume that knowledge of reality is formed on the basis that reality is a social construct, formed by the actions of various actors (Walsham, 1998, p. 376). This approach is close to the problem of using product placement in video games and product placement efficiency.

We selected the analysis of the use of product placement in two video games considering their popularity nowadays and product placement strategies: Final Fantasy XV and FIFA 19. A survey was conducted to analyze specific impact of constructs and statistic analysis was held using the software PLS to identify structured equation models and the factorial analysis supports, or not, the hypothesis of our framework. Thus, a quantitative descriptive study is presented in the results section of this paper.

\subsection{Data collection}

The survey method was used in this study to collect the data. The survey was conducted via Google Forms and it contained several sections. In the first section, gamers were informed that the information is treated in a confidential, anonymous and aggregated way, being used solely for academic purposes. In the second section of the survey, demographic questions were presented. In this section, there were four questions with answer options: about gender, age, educational level and games they play. In the third section, respondents were asked to watch a video containing an excerpt from the game Final Fantasy $\mathrm{XV}$ with product placement. The question did not indicate that there was product placement in the video. In the game Final Fantasy XV, via product placement, Nissin Cup Noodles were advertised. Participants of the game walk past a small kiosk with low-key advertising. In the fourth section of the survey, respondents were asked to answer questions regarding product placement in Final Fantasy XV - questions were related to the video that respondents watched in the previous section. In the fifth section, respondents were asked to watch a two-minute video in which product placement in FIFA 19 was present. In this video, there is an advertisement for several brands. Football players wear the PUMA brand 
uniform and there is an advertisement of Adidas, Chevrolet, and Kohler brands along the edges of the football field. Thus, the questions in the questionnaire concerned all the variables. Thanks to videos, video game users recalled what product placement looked like in games, and then answered questions about whether they had seen this ad while playing, how they reacted to it then and now, and so on. Questions concerned both the largest world brands and lesser-known brands.

The survey was answered using a Likert scale from 1 to 5 where 1 was related to totally disagreement and 5 totally agreement with the statement in each question. A pre test with 15 respondents was conducted to test the survey instrument and after little changes, the Google file link was shared on forums, groups on social media and directly by email and messengers to individuals that were related to the estimated sample. The period of collecting the answers for the survey was from the 11th of May to the 14th of May 2019 and we reach 465 respondents.

\subsection{Sample}

The survey participants were gamers who spend their time on thematic websites and forms - in other words, they are a part of video gamers community. All the 465 respondents, $53.8 \%$ of participants are males, $45.4 \%$ females, and $0.9 \%$ others and $67.7 \%$ of them are aged from 26 to 49 years old. Therefore, $41.1 \%$ of respondents have a master's degree and $35.1 \%$ have a bachelor degree.

\section{RESULTS}

To test the conceptual framework, we used a Partial Least Square-Structural Equation Modelling (PLS-SEM) approach. The use of PLS allows researchers to address accurately a wide range of problems (Hair et al., 2014). Using a twostage approach, and the support of the SmartPLS 3.0, we tested the presented model. The method of two-stage consists of an analysis of the outer model and the inner model (Hair et al., 2014). The external model was assessed to evaluate the reliability and validity of the measures considering the PLS-SEM algorithm.
We used the Composite Reliability (CR) score to assess the reliability of the constructs that is achieved when CR value exceeds 0.60 (Bagozzi \& Yi, 1988). Constructs can be considered reliable as all of the $\mathrm{CR}$ scores exceeded the indicated threshold. Thus, we checked the convergent and discriminant validity. If the Average Variance Extracted (AVE) value exceeds 0.50 (Fornell \& Larcker, 1981), then the convergent validity is achieved. We can conclude that convergent validity was achieved as the AVE scores were above the threshold. The discriminant validity was also tested, considering if the square root of the AVE value is above the Inter-Correlation (IC) (Fornell \& Larcker, 1981). The approach shows that discriminant validity is achieved, as the square roots of the AVE scores were all above the IC scores. Table 1 presents the descriptive, Cronbach's alpha, CR, IC and the AVE scores.

Table 1. Descriptive, Cronbach's alpha, CR, rho_A and AVE scores

\begin{tabular}{|c|c|c|c|c|}
\hline Factors & $\begin{array}{c}\text { Cronbach's } \\
\text { alpha }\end{array}$ & rho_A & $\begin{array}{l}\text { Composite } \\
\text { reliability }\end{array}$ & AVE \\
\hline Brand familiarity & 0.881 & 0.896 & 0.901 & 0.406 \\
\hline Brand recognition & 0.795 & 0.792 & 0.855 & 0.542 \\
\hline Emotional response & 0.950 & 0.956 & 0.955 & 0.589 \\
\hline Purchasing intention & 0.941 & 0.949 & 0.947 & 0.548 \\
\hline Product placement & 0.840 & 0.843 & 0.879 & 0.511 \\
\hline $\begin{array}{l}\text { Quality of virtual } \\
\text { reality }\end{array}$ & 0.858 & 0.860 & 0.904 & 0.701 \\
\hline
\end{tabular}

Further, we also examined the HeterotraitMonotrait (HTMT) ratio to check if the constructs have discriminant validity issue or not. According to Henseler et al. (2014), a threshold of 0.90 supports the discriminant validity. The data indicates that the discriminant validity was achieved as the HTMT ratio scores were all below the threshold (see Table 2).

Table 2. Discriminant validity-HTMT ratio scores

\begin{tabular}{l|c|c|c|c|c|c}
\hline \multicolumn{1}{c}{ Factors } & BF & BR & ER & PI & PP & QVR \\
\hline $\begin{array}{l}\text { Brand } \\
\text { familiarity }\end{array}$ & 0.637 & - & - & - & - & - \\
\hdashline $\begin{array}{l}\text { Brand } \\
\text { recognition }\end{array}$ & 0.718 & 0.736 & - & - & - & - \\
$\begin{array}{l}\text { Emotional } \\
\text { response }\end{array}$ & 0.768 & 0.548 & 0.767 & - & - & - \\
$\begin{array}{l}\text { Purchasing } \\
\text { intention }\end{array}$ & 0.788 & 0.612 & 0.877 & 0.741 & - & - \\
$\begin{array}{l}\text { Product } \\
\text { placement }\end{array}$ & -0.624 & -0.447 & -0.498 & -0.533 & 0.715 & - \\
$\begin{array}{l}\text { Quality of } \\
\text { virtual reality }\end{array}$ & 0.712 & 0.485 & 0.677 & 0.703 & -0.454 & 0.837 \\
\hline
\end{tabular}


Table 3. Hypotheses test

\begin{tabular}{l|c|c|c}
\hline \multicolumn{1}{c|}{ Variables } & Path coefficient & T-statistics & P-values \\
\hline Brand familiarity $\rightarrow$ emotional response & 0.768 & 38.469 & 12.889 \\
Brand recognition $\rightarrow$ brand familiarity & 0.487 & 72.665 \\
Emotional response $\rightarrow$ purchasing intention & 0.877 & 10.304 & 0.000 \\
Product placement $\rightarrow$ brand recognition & -0.447 & 11.134 & 0.000 \\
Product placement $\rightarrow$ quality of virtual reality & -0.454 & 12.154 & 0.000 \\
Quality of virtual reality $\rightarrow$ brand familiarity & 0.476 & 0.000 \\
\hline
\end{tabular}

\subsection{Hypotheses testing}

To test the research hypotheses, we evaluated the inner model. Hence, a bootstrapping procedure (499 subsamples) was conducted. Table 3 shows the results of the model and consequently the hypotheses testing.

The results support $\mathrm{H} 1 \quad(\mathrm{PC}=-0.44, p>0.000)$, which means that product placement perception is positively affecting on brand recognition. The result for $\mathrm{H} 2$ is also supported $(\mathrm{PC}=-0.45$, $p>0.000$ ), which means that product placement perception is positively affecting on virtual reality. The results also support $\mathrm{H} 3(\mathrm{PC}=0.48, p<0.000)$ that brand recognition positively affects the brand familiarity. Results for $\mathrm{H} 4(\mathrm{PC}=0.47, p<0.000)$ the quality of virtual reality positively impact on brand familiarity. Therefore, $\mathrm{H} 5$ is supported $(\mathrm{PC}=0.76, p<0.000)$ that means brand familiarity is positively affecting the emotional response. Finally, the results support also $\mathrm{H} 6(\mathrm{PC}=0.87$, $p<0.000)$ that emotional response has a positive impact on purchasing intention.

\section{DISCUSSION}

Next we discuss on the hypotheses that were compiled in our framework and indicate how the results correlate with them.

\section{H1: The product placement perception has a pos- itive impact on brand recognition.}

This hypothesis was confirmed in this study. Product placement is, in any case, the repetition of the brand name, which contributes to the brand's memorability, helps to recognize it. And although well-known brands took part in the research, the fact that the players remembered them confirms the impact of product placement on brand recog- nition. This hypothesis is supported by literature (Marti-Parreno et al., 2017; Mau et al., 2008). The results showed that most respondents saw the product placement of all brands advertised in Final Fantasy XV and FIFA 19 games. It can be said that explicit product placement is acceptable for players. But it should be borne in mind that the examples of product placement, considered in this study, are cases of unobtrusive advertising, which is close to real-life advertising.

\section{H2: The product placement has a positive impact on virtual reality.}

Respondents agreed that advertising makes the virtual reality of the game more realistic. Accordingly, this hypothesis was confirmed. The ideas of researchers discussed in the literature review are related to the findings (Dilworth, 2010; Wang \& Chen, 2019). The results showed that respondents agreed that Final Fantasy XV and FIFA 19 games have a high degree of realism, and product placement in them enhances the quality of virtual reality. Hence, the gamers perceive the virtual reality as highly realistic in those cases when the design of the game resembles reality, and, aspects such as advertising reinforce this feeling.

\section{H3: Brand recognition has a positive impact on brand familiarity.}

Brand recognition by players indicates that the brand is well known to the audience. This hypothesis was confirmed during the study. Researchers also proved that brand familiarity is a result of brand's influence on audience in any ways - to have a clear brand image in mind, the audience must recognize the brand first (Laroche et al., 1996; Mackay et al., 2009). Results showed that in Final Fantasy XV and FIFA 19 games, world-famous brands that most people know and several lesser-known brands (as Nissin Foods and Kohler) 
were advertised. Thus, brand Kohler recognized the smallest number of familiarity. About half of the respondents answered that the advertisement of the brand Kohler made them angry, the same number of respondents expressed dissatisfaction with the advertisement of other brands. In other words, there is no linear pattern between brand familiarity and the degree of dissatisfaction of the audience.

H4: Quality of virtual reality has a positive impact on brand familiarity.

In scientific literature, the quality of virtual reality is explored in connection with its impact on the audience and the effectiveness of advertising (Wang \& Chen, 2019). The quality of virtual reality is high in games chosen for analysis. Product placement in games is well recognizable. In this regard, many survey participants saw the brands in the game and acquired that they are familiar with these brands. Thus, the hypothesis was confirmed. We could see that users find the games more realistic (VR) in the cases where players are more familiar with the advertised brands.

\section{H5: Brand familiarity has a positive impact on emotional response.}

Any emotions caused by brand form its image (Machleit \& Wilson, 1988). All advertised brands were familiar to most players. Many brands advertised in games caused an emotional response in respondents. Most often, the emotions were positive. Negative emotions do not kill the desire to make a purchase: Respondents answered that their advertising makes them angry, but at the same time, they feel like buying products of the advertised brand. The survey did not consider other emotions besides happiness and anger, but it can be assumed that participants in any video games have more different emotions about product placement.

\section{H6: Emotional response has a positive impact on purchasing intention.}

The connection between the emotional response to the appearance of brands in the game and the desire to buy the products of these brands was found in the survey results. Researchers found similar results (Machleit \& Wilson, 1988). The results in this study showed that advertising of wellknown brands is so familiar to users that unobtrusive and they perceive non-aggressive product placement mostly positively. Respondents were aware that they see brand advertising in games, but they still declared a desire to make a purchase. Product placement in an interesting game with good graphics, integrated into the plot and unobtrusive, enhances the positive perception of brands by players.

\section{CONCLUSION}

In the modern world, product placement strategy is frequently used and causes mostly positive emotions among the audience, weary of obvious and intrusive advertising. Product placement is a hidden advertising, but now the audience often recognizes it, and that does not hinder the effectiveness of such advertising. Although the problem of product placement technology is ambiguous and depends on many conditions, it can be said that such advertising contributes to brand promotion, and makes it more recognizable and memorable, forms a positive attitude to the brand when advertising is well thought out and does not distract from the main content - art or entertainment - in which it was placed (since video games were considered in this study made it clear that product placement should not spoil the gaming experience).

The results of the study suggest that respondents are generally positive about product placement. Advertising in the game enhances its realism and does not distract from the gameplay. Advertised brands are mostly of interest and cause positive feelings. It is particularly interesting that most respondents are adults who are able to make purchases, including expensive brands, and have a fairly high level of education. However, it is important to bear in mind that all the brands in the questionnaire are already well known to the audience. 
Since branded entertainment is synonymous with product placement, it can be concluded that advertised brands should entertain the audience by mimicking artistic content and at the same time standing out. With regard to video games, this means that brand advertising must be present in the virtual reality of games, just as it presents in real life. In other words, advertising integration must be authentic. The player's interaction with brands during the game reinforces positive emotions and good attitude towards brands and may also cause a desire to purchase brand products. In each case, the problem of advertising integration of the brand into the game space should be solved based on the objectives of the brand and the content in which the advertisement will be placed.

\section{REFERENCES}

1. Babacan, E., Akcali, S. I., \& Baytekin, P. (2012). Product Placement as a Rising Marketing Communication Activity: An Assessment on Television Serials. Procedia - Social and Behavioral Sciences, 62, 13191331. https://doi.org/10.1016/j. sbspro.2012.09.226

2. Bagozzi, R. P., \& Yi, Y. (1988). On the Evaluation of Structure Equation Models. Journal of the Academy of Marketing Science, 16(1), 74-94. Retrieved from https:// link.springer.com/article/10.1007/ BF02723327

3. Chin, S., Wilson, B., \& Russo, A. (2013). Product Placement Redefined. Retrieved from https://www. academia.edu/17156392/Product placement_redefined (accessed on May 12, 2019).

4. Dilworth, J. (2010). Realistic Virtual Reality and Perception. Philosophical Psychology, 23(1), 23-42. Retrieved from https://philarchive. org/archive/DILRVRv1

5. Fornell, C., \& Larcker, D. (1981) Evaluating Structural Equation Models with Unobservable Variables and Measurement Error. Journal of Marketing Research, 18(1), 39-50. https://doi. org/10.2307/3151312

6. Glass, Z. (2007). The Effectiveness of Product Placement in Video Games. Journal of Interactive Advertising, 8(1), 23-32. https:// doi.org/10.1080/15252019.2007.1 0722134

7. Gorard, S. (2004). Quantitative Methods in Social Science: The Role of Numbers Made Easy. New York, London: Continuum.
8. Gupta, P., \& Lord, K. R. (1998). Product Placement in Movies: The Effect of Prominence and Mode on Audience Recall. Journal of Current Issues \& Research in Advertising, 20(1), 47-59. https:// doi.org/10.1080/10641734.1998.1 0505076

9. Hair, J., Hult, T., Ringle, C., \& Sarstedt, M. (2014). A Primer on Partial Least Squares Structural Equation Modeling (PLS-SEM) (15 p.). United States of America: Sage Publications,

10. Henseler, J., Ringle, C., \& Sarstedt, M. (2014). A new criterion for assessing discriminant validity in variance-based structural equation modeling. Journal of the Academy of the Marketing Science, 43(1), 115-135. Retrieved from https:// link.springer.com/article/10.1007/ s11747-014-0403-8

11. Hudson, S., \& Hudson, D. (2006). Branded Entertainment: A New Advertising Technique or Product Placement of Disguise? Journal of Marketing Management, 22(5-6), 489-504. https://doi. org/10.1362/026725706777978703

12. Humans of data (2018). Your Guide to Qualitative and Quantitative Data Analysis Methods. Retrieved from https://blog.socialcops.com/academy/resources/ qualitative-quantitative-dataanalysis-methods/\#section 1b1 (accessed on May 12, 2019).

13. Karrh, J. A., McKee, K. B., \& Pardun, C. J. (2003). Practitioners' Evolving Views on Product Placement Effectiveness. Journal of Advertising Research, 43(2), 138 149. Retrieved from https://www. cambridge.org/core/journals/ journal-of-advertising-research/ article/practitioners-evolvingviews-on-product-placementeffectiveness/69A29802ED7D871 A1535F5FE90D74432

14. Kit, L. C., \& Qui P’ng, E. L. (2014). The Effectiveness of Product Placement: The Influence of Product Placement towards Consumer Behavior of the Millennial Generation. International Journal of Social Science and Humanity, 4(2), 138-142. http://dx.doi. org/10.7763/IJSSH.2014.V4.334

15. Laroche, M., Kim, C., \& Zhou, L. (1996). Brand Familiarity and Confidence as Determinants of Purchase Intention: An Empirical Test in a Multiple Brand Context. Journal of Business Research, 37(2), 115-120. https://doi. org/10.1016/0148-2963(96)000562

16. Lehu, J.-M. (2009). Branded Entertainment: Product Placement $\&$ Brand Strategy in the Entertainment Business. Kogan Page.

17. Machleit, K. A., \& Wilson, D. (1988). Emotional Feelings and Attitude toward the Advertisement: The Roles of Brand Familiarity and Repetition. Journal of Advertising, 17(3), 27-35. Retrieved from https://www.jstor. org/stable/4188686?seq=1\#page _ scan_tab_contents

18. Mackay, T., Ewing, M., Newton, F., \& Windisch, L. (2009). The Effect of Product Placement in Video games on Brand Attitude and Recall. International Journal of Advertising, 28(3), 423438. https://doi.org/10.2501/ S0265048709200680 
19. Marti-Parreno, J., Bermejo-Berros, J., \& Aldas-Manzano, J. (2017). Product Placement in Video Games: The Effect of Brand Familiarity and Repetition of Consumers' Memory. Journal of Interactive Marketing, 38, 55-63. https://doi. org/10.1016/j.intmar.2016.12.001

20. Mau, G., Silberer, G., \& Constien, C. (2008). Communicating Brands Playfully. International Journal of Advertising, 25(5), 827-851. https://doi.org/10.2501/ S0265048708080293

21. Nelson, M. R. (2002). Recall of Brand Placements in Computer/ Video Games. Journal of Advertising Research, 42(2), 80-92. https:// doi.org/10.2501/JAR-42-2-80-92

22. Newell, J., Salmon, C. T., \& Chang, S. (2006). The Hidden History of Product Place- ment. Journal of Broadcasting \& Electronic Media, 50(4), 575-

594. https://doi.org/10.1207/

s15506878jobem5004_1

23. Parreno, J. M. (2015). Engaging Consumers through Branded Entertainment and Convergent Media. IGI Global.

24. Shrum, L. J. (2017). The Psychology of Entertainment Media: Blurring the Lines between Entertainment and Persuasion. London, New York: Routledge.

25. Walsham, G. (1995). The Emergence of Interpretivism in IS Research. Information Systems Research, 6(4), 376-394. Retrieved from https://www.jstor.org/ stable/23010981?seq=1\#page _ scan_tab_contents

26. Wang, Y., \& Chen, H. (2019). The Influence of Dialogic Engage- ment and Prominence on Visual Product Placement in Virtual Reality Videos. Journal of Business Research, 100, 493 502. https://doi.org/10.1016/j. jbusres.2019.01.018

27. Williams, K., Petrosky, A., Hernandez, E., \& Page, R. (2011). Product Placement Effectiveness: Revisited and Renewed. Journal of Management and Marketing Research, 7, 132-155. Retrieved from https://www.researchgate. net/publication/266733618_ Product_Placement_Effectiveness_Revisited_and_Renewed

28. Winkler, T., \& Buckner, K. (2006). Receptiveness of Gamers to Embedded Brand Messages in Advergames. Journal of Interactive Advertising, 8(1), 3-32. https://doi.org/10.1080/1525201 9.2006.10722123 